И

зучение роли полиморфизма генов, кодирующих цитокины, в развитии осложнений урогенитальной хламидийной инфекции у женщин

К.И. Плахова

ФГБУ «Государственный научный центр дерматовенерологии и косметологии» Минздрава России 107076, Москва, ул. Короленко, д. 3, стр. 6

\footnotetext{
Приведены результаты исследования полиморфизма генов, кодирующих цитокины IL-6, IL-10, TNF- $\alpha$, INF-y, TGF- $\beta_{1}$, a также MBL2, у женщин с урогенитальной хламидийной инфекцией (40 человек), женщин с вторичным бесплодием с хламидийной инфрекцией в анамнезе (20 человек) и клинически здоровых женщин репродуктивного возраста (группа контроля, 20 человек). Для изучения полиморфизма генов использован мультиплексный молекулярно-генетический метод SNapShot. В результате проведенных исследований для каждого полиморфизма генов цитокинов определены наиболее часто встречающиеся варианты генотипов. Установлены достоверные $(0,01<p<0,001)$ ассоциации между частотой распространенности отдельных вариантов генотипов (IL-6* $-174 \mathrm{C} / \mathrm{C}, \mathrm{IL}-10^{*}-1082 \mathrm{G} / \mathrm{A}, \mathrm{TGF}-\beta_{1}{ }^{*}-915 \mathrm{G} / \mathrm{C}, \mathrm{TGF}-\beta_{1}{ }^{*}-869 \mathrm{~T} / \mathrm{C}$ и MBL2*-204G/G) с развитием осложнений урогенитальной хламидийной инфекции, что позволяет рассматривать данные варианты генотипов в качестве маркеров повышенного риска осложненного течения урогенитальной хламидийной инсрекции, приводящего к нарушениям репродуктивной срункции, у женщин.
}

Ключевые слова: урогенитальная хламидийная инфекция у женщин, осложнения, В3ОМТ, нарушения репродуктивной функции, трубное бесплодие, полиморфизмы генов цитокинов, генотипы IL-6* ${ }^{*} 174 C / C$,

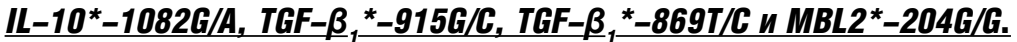

Контактная информация: plahova_xenia@mail.ru. Вестник дерматологии и венерологии 2013; (4): 44—51.

\title{
A study of the role played by the polymorphism of genes encoding cytokines in the development of complications of the urogenital chlamydia infection in Women
}

\author{
K.I. Plakhova
}

State Research Center of Dermatovenereology and Cosmetology, Ministry of Healthcare of the Russian Federation Korolenko str 3, bldg 6, 107076, Moscow, Russia

The author describes the results of a study of the polymorphism of genes encoding cytokines IL-6, IL-10, TNF- $\alpha$, IFN- $\gamma$, TGF- $\beta$, and MBL2 in women suffering from the urogenital chlamydia infection (40 subjects), women with secondary infertility caused by the Chlamydia infection in the medical history (20 subjects) and clinically healthy women of childbearing potential (control group, 20 subjects). The SNapShot multiplex molecular and genetic method was used to study the polymorphism of genes.

As a result of the study, the most frequent genotypes were revealed for each polymorphism of cytokine genes. Reliable associations $(0.01<p<0.001)$ were established between the frequency of individual genotypes $\left(I L 6^{*}-174 C / C\right.$, IL-10*-1082G/A, TGF- $\beta_{1}{ }^{*}-915 G / C$, TGF- $\beta_{1}{ }^{*}-869 T / C$ and MBL2 ${ }^{*}-204 G / G$ ) and the onset of complications of the urogenital chlamydia infection, which makes it possible to examine these variants of genotypes as markers of an increased risk for the complicated course of the urogenital chlamydia infection resulting in reproductive disorders in women.

Key words: urogenital chlamydia infection in women, complications, pelvic inflammatory diseases, reproductive disorders, tubal infertility, polymorphisms of cytokine genes, IL6*-174C/C, IL-10*-1082G/A, TGF- $\underline{\beta}_{1}{ }_{-}-915 G / C$, TGF- $\beta_{1}{ }^{*}-869 T / C$ and MBL2*-204G/G genotypes. 
Заболеваемость урогенитальной хламидийной инфекцией (УГХИ) в Российской Федерации занимает первое место среди всех бактериальных инфекций, передаваемых половым путем, и составила в 2011 г. 65,9 на 100000 населения [1]. УГХИ у женщин часто приводит к развитию осложнений со стороны урогенитального тракта, таких как воспалительные заболевания органов малого таза (ВЗОМТ) и трубное бесплодие, что может быть обусловлено особенностями генотипа человека. Известно, что полиморфизм в регуляторных областях генов, кодирующих про- и противовоспалительные цитокины, может предопределять индивидуальную предрасположенность к развитию осложненного клинического течения аутоиммунных, иммуносупрессивных и воспалительных процессов в ответ на действие патологического агента. Наиболее часто в качестве генов, ассоциированных с развитием бесплодия у лиц, перенесших урогенитальный хламидиоз, в литературе указываются гены, кодирующие цитокины интерлейкин-10 (IL-10), туморнекротизирующий фактор (TNF), интерферон-ү (IFN-ү) [2-4]. В то же время проблема прогнозирования осложненного клинического течения УГХИ, сопровождающегося осложнениями, в том числе бесплодием, на основании изучения полиморфизмов генов, кодирующих про- и противовоспалительные цитокины, на данный момент изучена недостаточно.

Целью исследования явилось изучение роли полиморфизма функционально значимых участков генов, кодирующих цитокины, в развитии осложнений УГХИ у женщин.

\section{Материал и методы}

В исследование включено 80 женщин, разделенных на 4 группы: 20 больных УГХИ нижних отделов мочеполового тракта (уретрит, цервицит); 20 больных осложненной УГХИ с поражением органов малого таза и других мочеполовых органов (сальпингит, сальпингоофорит, эндометрит); 20 больных вторичным бесплодием с неоднократными эпизодами УГХИ в анамнезе; 20 клинически здоровых женщин репродуктивного возраста.

В отобранных генах изучали следующие однонуклеотидные замены: $-308 A / G$ (rs 1800629) в TNF-A; $-592 A / C$ (rs1800872), -1082A/G (rs1800896) и -819T/C (rs1800871) в IL-10; 915G/C (rs1800471) и 869T/C (rs 1982073) в TGF- $\beta_{1} ; 204 G / A$ (rs 1800450) в $M B L 2,-174 G / C$ (rs 1800795) в IL-6; 874T/A (rs61923114) в IFN- $\gamma$.

Материалом для изучения полиморфизмов генов TNF-A, IL-10 TGF- $\beta_{1}, M B L 2, I L-6$ и IFN- $\gamma$ являлась геномная ДНК человека, выделенная из лейкоцитов перифрерической крови.

Для анализа полиморфизмов генов использовали метод SNaPshot. Реакция SNaPshot основана на детекции методом секвенирования присоединенного к специфическому праймеру дидезоксинуклеотида, несущего фрлюоресцентную метку. В ходе реакции происходит присоединение дидезоксинуклеотида, комплементарного позиции SNP, к 3'-концу праймера и последующая детекция продукта присоединения методом капиллярного электрофореза.

Исследование включало следующие этапы: получение биологических образцов, подбор праймеров для амплификации выбранных для изучения полиморфизмов генов и постановки реакции SNaPshot; выделение ДНК из биообразцов; амплификация ДНК выбранных генов, включающих исследуемые однонуклеотидные полиморфизмы, для последующей постановки реакции SNaPshot; проведение мультиплексной реакции SNaPshot co специфическими праймерами; анализ меченых SNaPshot-праймеров капиллярным электрофорезом на секвенаторе.

Кровь для исследования в количестве 4-5 мл брали в вакутейнеры, в которых содержалась этилендиаминтетрауксусная кислота в качестве стабилизатора свертывания крови.

Для изучения полиморфизмов отобранных генов были подобраны праймеры для амплификации и секвенирования участков генов, несущих однонуклеотидные полиморфизмы. Последовательности генов были найдены в базе данных NCBI http://www.ncbi. nlm.nih.gov. Затем внутри полученных последовательностей генов с помощью программы Vector NTI были подобраны праймеры для амплификации фрагментов генов, содержащих позиции изучаемых полиморфизмов. Температура отжига для всех праймеров составляла $64^{\circ} \mathrm{C}$.

Выделение ДНК из образцов крови проводилось по стандартной процедуре с использованием коммерческого набора реагентов DiatomTM DNA Prep 100 (фирма «Изоген», Россия) с применением лизирующего реагента, содержащего гуанидинтиоционат.

Амплификацию ДНК проводили на термоциклеpe DNAEngineDyad (BioRad, США) с использованием следующих компонентов (конечная концентрация в полимеразной цепной реакции ПЦР): 1 × Таq буфер, 2,5 мМ ионы магния, 2,5 мМ смесь dNTPs, 1-2 Ед. Таq-полимеразы, праймеры по 20 пмоль каждый, 200 нг геномной ДНК человека. Рекомендованные условия амплификации отобранных для исследования генов: 1 цикл: $95{ }^{\circ} \mathrm{C}-5$ мин.; 30 циклов: $95{ }^{\circ} \mathrm{C}-30$ с.; $64{ }^{\circ} \mathrm{C}-20$ с.; $72{ }^{\circ} \mathrm{C}-30$ с.; 1 цикл: $72{ }^{\circ} \mathrm{C}-10$ мин.

Полученный ПЦР-продукт очищали методом ExolSAP. Для каждого образца использовали 2 Ед. щелочной фосфратазы SAP, 2 Ед. экзонуклеазы Exol, деионизованную воду (до объема 10 мкл) и 4 мкл ПЦРпродукта. Инкубацию проводили при $37^{\circ} \mathrm{C}$ в течение 1 ч. Затем инактивировали фермент при $72{ }^{\circ} \mathrm{C}$ в течение 15 мин. Очищенные продукты ПЦР использовали в реакции SNaPshot. 
Для постановки реакции SNaPshot готовили реакционную смесь, используя реактивы набора ABI PRISM $^{\circledR}$ SNaPshot ${ }^{\mathrm{TM}}$ MultiplexKit: 5 мкл SNaPshotReadyReactionMix, 1 мкл SNaPshot-праймера (0,15 пмоль/мкл), 1 мкл очищенной матрицы (ДНК) (0,15 пмоль/мкл) и 3 мкл деионизованной воды. В состав реакционной смеси SNaPshotReadyReactionMix входят ДНК-полимераза AmpliTaq, фрлюоресцентно меченные дидезоксинуклеозидтрифосфраты и буфер. Для постановки контрольной реакции готовили смесь: 5 мкл SNaPshot Ready Reaction Mix, 1 мкл контрольного праймера, 2 мкл pGEM-3Zf (+) и 2 мкл деионизованной воды. Для постановки отрицательного контроля вместо pGEM-3Zf использовали 2 мкл деионизованной воды.

Проведение реакции SNaPshot осуществлялось с использованием рекомендуемой фирмой-производителем программы амплификации, включающей 25 циклов: $96{ }^{\circ} \mathrm{C}-10$ с., $50{ }^{\circ} \mathrm{C}-5$ с., $60{ }^{\circ} \mathrm{C}-30$ с. Для очистки реакционной смеси от несвязавшихся фрлюоресцентно меченных дидезоксинуклеозидтрифосфратов добавляли фермент $(0,5$ Ед. щелочной фросфратазы SAP) и проводили инкубацию при $37^{\circ} \mathrm{C}$ в течение 1 ч. Затем инактивировали фрермент при $72{ }^{\circ} \mathrm{C}$ в течение 15 мин.

Статистическая обработка результатов исследования проводилась с использованием пакета программ: Statistica for Windows 6,1 (Statsoft Inc., США) и программного обеспечения MS Excel (Microsoft). Описательная статистика качественных признаков (определение частоты встречаемости полиморфизмов генов) представлена абсолютными и относительными частотами. Сравнение несвязанных групп по качественным признакам (попарное сравнение частот молекулярногенетических показателей в группах больных и здоровых лиц, а также между группами больных) осуществляли с использованием двустороннего критерия $\mathrm{X}^{2}$ для таблиц сопряженности $2 \times 2$. Различия считали статистически значимыми при $p \leq 0,05$. Силу ассоциаций оценивали в значениях показателя отношения шансов odds ratio (OR).

\section{Результаты исследования}

Результаты изучения у пациенток частоты распространения полиморфизмов функционально значимых участков генов, отобранных для исследования, представлены в таблице.

В результате изучения полиморфизма отобранных генов были получены данные о распределении частот генотипов в исследованной выборке пациенток. В каждой изученной позиции генов выявлено распределение трех вариантов генотипа (два гомозиготных и один гетерозиготный), за исключением гена TGF- $\beta$, в позиции - 915, для которого выявлялись два варианта генотипа (гомозиготный и гетерозиготный).
В общей выборке пациенток для каждого исследованного полиморфизма были определены наиболее часто встречающиеся варианты генотипов (рис. 1).

Среди изученных генотипов наиболее часто встречались: генотип C/C гена IL-10 (позиция $592)$ - в 46,3\% случаев; генотип $G / A$ гена $I L-10$ (позиция - 1082) - в 50,0\%; генотип $C / C$ гена $I L-10$ (позиция - 819) - в 41,2\%; генотип $G / G$ гена $T N F-A$, (позиция - 308) - в 62,5\%; генотип T/A гена IFN-ү (позиция - 874) - в 82,4\%; генотип $G / C$ гена IL-6 (позиция - 174) - в 38,7\%; генотип $G / A$ гена $M B L$ (позиция - 204) - в 80,0\%; генотип $G / G$ гена $T G F-\beta_{1}$ (позиция - 915) - в 83,7\%; генотип $T / T$ гена $T G F-\beta_{1}$ (позиция - 869) - в 53,7\%.

В результате проведенных исследований были получены данные о распределении частоты распространения полиморфизмов функционально значимых участков генов, отобранных для исследования.

\section{Ген цитокина IL-10}

При исследовании полиморфизма $I L-10^{*} C-592 A$ в обследованной выборке получено следующее распределение аллелей: C - 62,5\% (100); A - 37,5\% (60).

Генотип IL-10*-592C/C встречался у 37,5\% обследованных женщин. Частота регистрации данного генотипа в группах обследованных колебалась от 35,0 до $70,0 \%$. Следует отметить, что генотип IL-10*-592C/C статистически достоверно чаще встречался среди обследованных пациенток с вторичным (трубным) бесплодием по сравнению с пациентками с УГХИ - 70,0 и 37,5\% соответственно (OR = 3,89; $\left.\mathrm{X}^{2}=5,64 ; p<0,05\right)$ и здоровыми женщинами $-70,0$ и 40,0\% соответственно (OR $\left.=4,67 ; x^{2}=5,87 ; p<0,05\right)$. Это позволяет рассматривать генотип IL-10*-592C/C и аллель С в качестве возможного маркера повышенного риска развития бесплодия у женщин. Аллель $\mathrm{C}$ на сегодняшний день рассматривается исследователями как аллель риска, поскольку наличие этого аллеля приводит к увеличению уровня экспрессии IL-10 и, как следствие, к модификации иммунного ответа организма на инвазию патогена [5].

Генотип $I L-10^{*}-592 A / A$ являлся наиболее редким аллельным вариантом в исследованной выборке 20,0\% случаев; в группах пациенток он встречался с частотой от 0 до $30,0 \%$. Генотип IL-10*-592A/A статистически достоверно реже встречался среди обследованных пациенток с вторичным (трубным) бесплодием по сравнению с пациентками с УГХИ (0,0 и 25,0\% соответственно (OR $=0,16 ; X^{2}=3,56$; $p=0,05))$ и здоровыми женщинами - (0 и 30\% соответственно (OR $\left.=0,12 ; \mathrm{X}^{2}=4,33 ; p<0,05\right)$ ). Это позволяет рассматривать генотип IL-10*-592A/A и аллель А в качестве возможного протектора в отношении развития бесплодия у женщин. Наличие аллеля $\mathrm{A}$, так называемого протективного аллеля (генотипы $C A$ 


\begin{tabular}{|c|c|c|c|c|c|c|c|c|}
\hline Таблица & \multicolumn{8}{|c|}{$\begin{array}{l}\text { Частота распространения полиморсрных вариантов генов у женщин с УГХИ нижних отделов урогени- } \\
\text { тального тракта (1-я группа) и органов малого таза (2-я группа), женщин с вторичным (трубным) } \\
\text { бесплодием (3-я группа) и клинически здоровых женщин репродуктивного возраста (4-я группа), } \\
\text { абс. (\%) }\end{array}$} \\
\hline Ген & Позиция & Генотип & $\begin{array}{c}\text { Группа } 1 \\
(n=20)\end{array}$ & $\begin{array}{c}\text { Группа } 2 \\
(n=20)\end{array}$ & $\begin{array}{l}\text { Всего } \\
\text { пациенток } \\
\text { с УГХИ } \\
(n=40)\end{array}$ & $\begin{array}{c}\text { Группа } 3 \\
(n=20)\end{array}$ & $\begin{array}{c}\text { Группа } 4 \\
(n=20),\end{array}$ & $\begin{array}{l}\text { Общая } \\
\text { выборка } \\
(n=80)\end{array}$ \\
\hline \multirow[t]{9}{*}{ IL-10 } & \multirow{3}{*}{$\begin{array}{c}C(-592) A \\
(r s 1800872)\end{array}$} & $C C$ & $7(35,0)$ & $8(40,0)$ & $15(37,5)$ & $14(70,0)$ & $8(40,0)$ & $37(46,3)$ \\
\hline & & $A C$ & $8(40,0)$ & $7(35,0)$ & $15(37,5)$ & $6(30,0)$ & $6(30,0)$ & $27(33,7)$ \\
\hline & & $A A$ & $5(25,0)$ & $5(25,0)$ & $10(25,0)$ & $0(0,0)$ & $6(30,0)$ & $16(20,0)$ \\
\hline & \multirow{3}{*}{$\begin{array}{c}G(-1082) A \\
(r s 1800896)\end{array}$} & $A A$ & $6(30,0)$ & $6(30,0)$ & $12(30,0)$ & $5(25,0)$ & $6(30,0)$ & $23(28,7)$ \\
\hline & & $G A$ & $7(35,0)$ & $12(60,0)$ & $19(47,5)$ & $11(55,0)$ & $10(50,0)$ & $40(50,0)$ \\
\hline & & $G G$ & $7(35,0)$ & $2(10,0)$ & $9(22,5)$ & $4(20,0)$ & $4(20,0)$ & $17(21,3)$ \\
\hline & \multirow{3}{*}{$\begin{array}{c}C(-819) T \\
(r s 1800871)\end{array}$} & $C C$ & $10(50,0)$ & $6(30,0)$ & $16(40,0)$ & $11(55,0)$ & $6(30,0)$ & $33(41,2)$ \\
\hline & & $C T$ & $6(30,0)$ & $7(35,0)$ & $13(32,5)$ & $6(30,0)$ & $10(50,0)$ & $29(36,2)$ \\
\hline & & $T T$ & $4(20,0)$ & $7(35,0)$ & $11(27,5)$ & $3(15,0)$ & $4(20,0)$ & $18(22,6)$ \\
\hline \multirow[t]{3}{*}{$T N F-A$} & \multirow{3}{*}{$\begin{array}{c}G(-308) A \\
(r s 1800629)\end{array}$} & $G G$ & $11(60,0)$ & $14(70,0)$ & $25(62,5)$ & $13(65,0)$ & $12(60,0)$ & $50(62,5)$ \\
\hline & & $G A$ & $8(40,0)$ & $6(30,0)$ & $14(35,0)$ & $3(15,0)$ & $7(35,0)$ & $24(30,0)$ \\
\hline & & $A A$ & $1(5,0)$ & $0(0,0)$ & $1(5,0)$ & $4(20,0)$ & $1(5,0)$ & $6(7,5)$ \\
\hline \multirow[t]{3}{*}{$I F N-\gamma$} & \multirow{3}{*}{$\begin{array}{c}T(874) A \\
(r s 61923114)\end{array}$} & $T T$ & $1(5,0)$ & $0(0,0)$ & $1(2,5)$ & $6(30,0)$ & $0(0,0)$ & $7(8,8)$ \\
\hline & & $T A$ & $17(85,0)$ & $18(90,0)$ & $35(87,5)$ & $11(55,0)$ & $20(100,0)$ & $66(82,4)$ \\
\hline & & $A A$ & $2(10,0)$ & $2(10,0)$ & $4(10,0)$ & $3(15,0)$ & $0(0,0)$ & $7(8,8)$ \\
\hline \multirow[t]{3}{*}{$I L-6$} & \multirow{3}{*}{$\begin{array}{c}G(-174) C \\
(r s 1800795)\end{array}$} & $C C$ & $4(20,0)$ & $8(40,0)$ & $12(30,0)$ & $14(70,0)$ & $4(20,0)$ & $30(37,5)$ \\
\hline & & $G C$ & $11(55,0)$ & $6(30,0)$ & $17(42,5)$ & $4(20,0)$ & $10(50,0)$ & $31(38,7)$ \\
\hline & & $G G$ & $5(25,0)$ & $6(30,0)$ & $11(27,5)$ & $2(10,0)$ & $6(30,0)$ & $19(23,7)$ \\
\hline \multirow[t]{3}{*}{$M B L$} & \multirow{3}{*}{$\begin{array}{c}G(-204) A \\
(r s 1800450)\end{array}$} & $G G$ & $1(5,0)$ & $6(30,0)$ & $7(17,5)$ & $3(15,0)$ & $2(10,0)$ & $12(15,0)$ \\
\hline & & GA & $19(95,0)$ & $14(70,0)$ & $33(82,5)$ & $15(75,0)$ & $16(80,0)$ & $64(80,0)$ \\
\hline & & $A A$ & $0(0,0)$ & $0(0,0)$ & $0(0,0)$ & $2(10,0)$ & $2(10,0)$ & $4(5,0)$ \\
\hline \multirow[t]{6}{*}{$T G F-\beta_{1}$} & \multirow{3}{*}{$\begin{array}{c}G(-915) C \\
(r s 1800471)\end{array}$} & $C C$ & $0(0,0)$ & $0(0,0)$ & $0(0,0)$ & $0(0,0)$ & $0(0,0)$ & $0(0,0)$ \\
\hline & & $G G$ & $19(95,0)$ & $13(65,0)$ & $32(80,0)$ & $16(80,0)$ & $19(95,0)$ & $67(83,7)$ \\
\hline & & $G C$ & $1(5,0)$ & $7(35,0)$ & $8(20,0)$ & $4(20,0)$ & $1(5,0)$ & $13(16,3)$ \\
\hline & \multirow{3}{*}{$\begin{array}{c}T(-869) C \\
(\text { rs1982073) }\end{array}$} & $T T$ & $15(75,0)$ & $7(35,0)$ & $22(55,0)$ & $12(60,0)$ & $9(45,0)$ & $43(53,7)$ \\
\hline & & $T C$ & $3(15,0)$ & $10(50,0)$ & $13(32,5)$ & $4(20,0)$ & $10(50,0)$ & $27(33,7)$ \\
\hline & & $C C$ & $2(10,0)$ & $3(15,0)$ & $5(12,5)$ & $4(20,0)$ & $1(5,0)$ & $10(12,5)$ \\
\hline
\end{tabular}

и $A A)$ исследователи связывают со сниженной продукцией IL-10 [5].

Генотип IL-10*-592A/C регистрировался в общей выборке обследованных с частотой $33,7 \%$; в группах пациенток обнаруживался с частотой 30,0-40,0\%. Достоверных различий в частоте данного генотипа между группами обследуемых установлено не было.

При изучении полиморфизма IL-10*C-819T в исследованной выборке получено следующее распределение аллелей: C - 59,4\% (95); Т - 40,6 \% (65).
Установлено, что генотип IL-10*-819C/C - наиболее частый вариант в обследованной выборке женщин и встречался у 41,2\% обследованных (30,0-55,0\% в отдельных группах), но не среди женщин группы контроля, в этой группе наиболее распространен генотип IL-10*-819C/T (50,0\% случаев). В общей выборке частота выявления генотипа составила $36,2 \%$.

Наименее частым вариантом полиморфизма $I L-10^{\star} C-819 T$ в исследованной выборке пациенток явился генотип IL-10*-819T/T (22,6\%) (20,0-35,0\% 


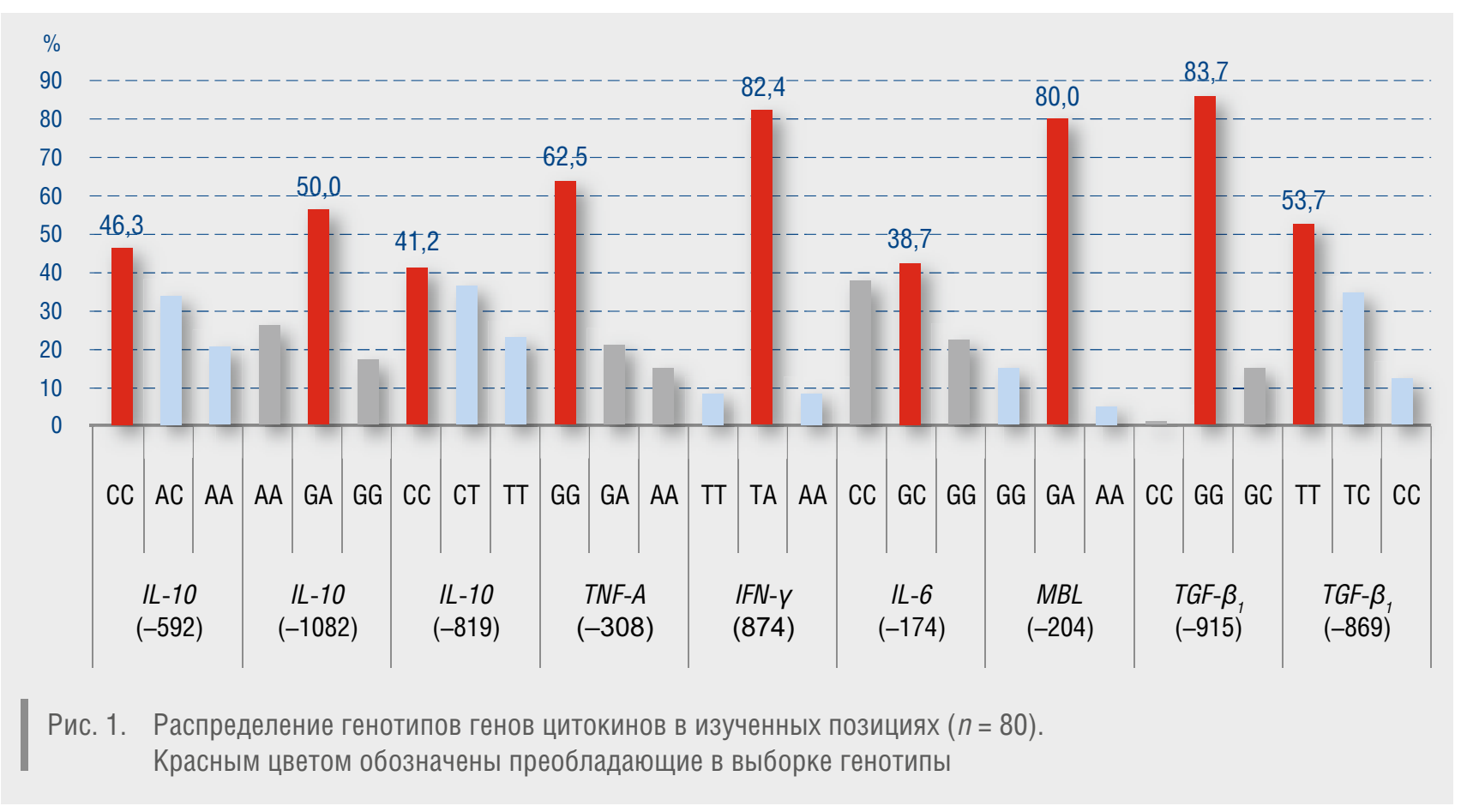

в группах пациенток). Достоверных различий в частоте встречаемости различных аллелей гена IL-10 в позиции -819 между группами пациенток не выявлено.

Аллели при изучении полиморфизма IL-10* G -1082A распределились следующим образом: $\mathrm{G}-45,0 \%$ (72); A $-55,0 \%$ (88).

Генотип IL-10*-1082A/A регистрировался в общей выборке обследованных с частотой $28,7 \%$ и обнаруживался с близкой частотой во всех группах пациенток (25,0-30,0\%). Достоверных различий в частоте регистрации генотипа между группами обследуемых установлено не было.

Генотип IL-10*-1082G/A был наиболее частым вариантом полиморфизма $I L-10^{\star} G-1082$ в исследованной выборке пациенток (50,0\%) и наблюдался у 35,0-60,0\% женщин. Данный генотип достоверно чаще встречался у женщин с хламидийной инфекцией органов малого таза в сравнении с группой пациенток с хламидийной инфекцией нижних отделов урогенитального тракта (60 и 35\% соответственно; OR = 2,79; $\left.\mathrm{X}^{2}=2,50 ; p=0,01\right)$, что позволяет рассматривать его в качестве маркера повышенного риска развития осложнений УГХИ.

Генотип IL-10*-1082G/G - наиболее редкий среди обследованных женщин и встречался в 21,3\% случаев (в разных группах пациенток частота колебалась от 10,0 до 35,0\%). Данный генотип достоверно реже выявлялся у женщин с хламидийной инфекцией органов малого таза в сравнении с группой пациенток с хламидийной инфекцией нижних отделов урогенитального тракта (10 и 35\% соответственно; OR = 0,21;
$\left.\mathrm{X}^{2}=3,58 ; p=0,05\right)$, что позволяет рассматривать его в качестве вероятного протектора развития осложнений УГХИ.

\section{Ген TNF-A}

По результатам изучения полиморфизма TNF-A* G-308A получено следующее распределение аллей в обследованной выборке: A - 22,5\% (36); G - 77,5\% (124).

Генотип TNF-A*-308G/G встречался в общей выборке пациенток наиболее часто (62,5\%; в отдельных группах от 60,0 до $70,0 \%$ ). Генотип TNF- $A^{*}-308 G / A$ встречался реже: в общей группе обследованных $30,0 \%$ (в отдельных группах пациенток 30,0-40,0\%). Генотип TNF-A*-308A/A был наиболее редким аллельным вариантом полиморфизма в обследованной выборке (7,5\%). Достоверных различий в частоте встречаемости различных аллелей гена TNF-A между группами пациенток выявлено не было.

\section{Ген IFN-Y}

По результатам изучения полиморфизма IFN- $\gamma^{\star} T-874 A$ получено следующее распределение аллей в обследованной выборке: Т - 50,0\% (80); А - 50,0\% (80).

Генотип IFN-Y $\gamma^{\star} 874 T / A$ - наиболее частый вариант в исследованной выборке пациенток (82,4\%). Частота регистрации генотипа в группах пациенток составила 55,0-100,0\%. В сравнении с пациентками с бесплодием генотип IFN- $\gamma^{\star} 874 T / A$ достоверно чаще встречался у клинически здоровых женщин $\left(\mathrm{OR}=0,06 \pm ; \mathrm{X}^{2}=8,53\right.$; $p<0,01)$ и женщин, больных УГХИ $\left(\mathrm{OR}=0,17 ; \mathrm{X}^{2}=7,87\right.$; $p<0,01)$. Данный генотип можно рассматривать как 
вероятный протектор в отношении развития вторичного (трубного) бесплодия у женщин.

Генотип IFN- $\gamma^{\star} 874 T / T$ - редкий вариант полиморфизма IFN- $\gamma^{\star} T-874 A$ в исследованной выборке (8,8\%; в отдельных группах 0,0-30\%). Наличие варианта Т/T более характерно для пациенток с бесплодием, чем для здоровых $\left(\mathrm{OR}=8,14 ; \mathrm{X}^{2}=4,33 ; p<0,05\right)$ и пациенток с УГХИ (OR $\left.=8,14 ; X^{2}=4,33 ; p<0,05\right)$. В этой связи генотип IFN- $\gamma^{\star} 874 T / T$ можно рассматривать как возможный маркер (предиктор) повышенного риска развития бесплодия у женщин.

Других достоверных различий в частоте регистрации данного генотипа между группами обследуемых не установлено.

Аллельная комбинация A/A полиморфизма IFN- $\gamma^{\star} T-874 A$ в исследованной выборке пациенток встречалась достаточно редко (от 0,0 до $15,0 \%$ в отдельных группах пациенток).

\section{Ген IL-6}

По результатам изучения полиморфизма IL-6* G-174C было получено следующее распределение аллей в обследованной выборке: G - 45,0\% (72); C $55,0 \%(88)$.

Генотип IL-6 * $174 C / C$ регистрировался у $37,5 \%$ обследованных. Различия в частоте выявления данного генотипа между группами больных урогенитальной хламидийной инфекцией с поражением органов малого таза (40\%) и нижних отделов урогенитального тракта (20\%) оказались статистически достоверными $\left(\mathrm{OR}=2,7 ; \mathrm{X}^{2}=1,9 ; p=0,05\right)$. Кроме того, данный генотип достоверно чаще встречался в группе пациенток с вторичным (трубным) бесплодием по сравнению с больными урогенитальной хламидийной инфекцией нижних отделов урогенитального тракта) (OR=9,33; $\left.\mathrm{X}^{2}=10,1 ; p=0,001\right)$ и здоровых $\left(\mathrm{OR}=9,33 ; \mathrm{X}^{2}=10,1\right.$; $p=0,001)$. В связи с вышеизложенным данный генотип может рассматриваться как предиктор развития осложнений урогенитальной хламидийной инфекции и вторичного бесплодия у больных урогенитальной хламидийной инфекцией.

Генотип IL-6*174G/C в изученной выборке был достаточно распространенным и регистрировался у 38,7\% обследованных; в отдельных группах пациенток с частотой 20,0-55,0\%. Среди пациенток группы контроля и пациенток с хламидийной инфекцией органов малого таза этот вариант оказался наиболее распространенным - 50,0 и 55,0\% случаев соответственно, в то время как для пациенток с вторичным бесплодием и хламидийной инфекцией органов малого таза наиболее характерен генотип $I L-6^{\star} 174 C / C$ 70,0 и 40,0\% соотвественно. Генотип IL-6*174G/G в обследованной выборке пациенток встречался наиболее редко (23,7\%). Статистически значимых различий между группами пациенток для генотипов G/C и G/G не выявлено.

\section{Ген $M B L$}

Получено следующее распределение аллей в обследованной выборке: $\mathrm{G}-55,0 \%$ (88); $\mathrm{A}-45,0 \%$ (72).

Генотип MBL2*204G/A был наиболее распространенным вариантом и встречался среди всех обследованных в 80,0\% случаев. Достоверных различий в частоте регистрации данного генотипа между группами обследуемых не выявлено. Другие варианты генотипов были представлены реже. Частота регистрации генотипа $M B L 2^{\star} 204 G / G$ в группах обследованных составляла 5,0-30,0\%, в общей выборке $15,0 \%$. Разница между частотой регистрации генотипа MBL2*204G/G в группах пациенток с урогенитальной хламидийной инфекцией органов малого таза $(30,0 \%)$ и нижних отделов урогенитального тракта $(5,0 \%)$ оказалась статистически достоверной (OR = 8,$\left.14 ; X^{2}=4,3 ; p<0,05\right)$. В связи с вышеизложенным данный генотип может рассматриваться как возможный маркер риска развития осложнений у больных УГХИ. Однако окончательное заключение о роли данного генотипа в развитии осложнений УГХИ может быть сделано при увеличении объема выборки.

Генотип MBL2*204AVA не был обнаружен в группах пациенток с хламидийной инфекцией, однако встречался в группе контроля и в группе больных вторичным бесплодием (по 10,0\% случаев в группе).

\section{Ген TGF- $\beta_{1}$}

По результатам изучения полиморфизма $T G F-\beta_{1}^{*} G-915 C$ получено следующее распределение аллей в обследованной выборке: G - 91,8\% (147); C $8,1 \%(13)$.

Генотип TGF- $\beta_{1}{ }^{*} 915 C / C$ в исследованной выборке пациентов не встречался.

Генотип TGF- $\beta_{1}{ }^{*} 915 G / G$ регистрировался наиболее часто (у 83,7\% обследованных, в отдельных группах 65,0-95,0\%). Достоверных различий в частоте регистрации данного генотипа между группами обследуемых не выявлено.

Частота регистрации генотипа TGF- $\beta_{1}{ }^{*} 915 G / C$ в разных группах пациенток различалась (от 5,0 до 35,0\%), а в выборке в целом составила 16,3\%. При проведении статистической обработки было установлено, что генотип TGF- $\beta_{1}{ }^{*} 915 G / C$ наиболее характерен для пациенток с хламидийной инфекцией органов малого таза в сравнении с пациентками с хламидийной инфекцией нижних отделов урогенитального тракта $(\mathrm{OR}=10,23$; $\left.\mathrm{X}^{2}=5,63 ; p<0,05\right)$, а также по сравнению с группой здоровых женщин. В связи с вышеизложенным данный генотип может рассматриваться как маркер повышенного риска развития воспалительных заболеваний органов малого таза при УГХИ.

По результатам изучения полиморфизма $T G F-\beta_{1}{ }^{*} T-869 C$ получено следующее распределение аллей в обследованной выборке: Т - 70,6\% (113); C $-29,4 \%(47)$. 
Установлено, что генотип TGF- $\beta_{1}{ }^{*} 869 T / T$ среди обследованных регистрировался наиболее часто $(53,7 \%)$. При этом частота его регистрации в группах пациентов различалась: данный генотип встречался у $75,0 \%$ лиц с хламидийной инфекцией нижних отделов урогенитального тракта и почти в 2 раза реже $(35,0 \%)-$ у пациенток с хламидийной инфекцией органов малого таза; различия между данными группами оказались статистически достоверными $(\mathrm{OR}=0,18$; $\left.\mathrm{X}^{2}=5,58 ; p<0,05\right)$, что позволяет рассматривать данный генотип в качестве протектора развития осложнений УГХИ у женщин. Других достоверных различий между группами не выявлено.

Генотип TGF- $\beta_{1}{ }^{*} 869 T / C$ по частоте регистрации занял промежуточное положение (частота регистрации в выборке 33,8\%). Он встречался у $15,0 \%$ лиц с хламидийной инфекцией нижних отделов урогенитального тракта и в 3 раза чаще (у $50,0 \%$ ) у больных с хламидийной инфрекцией органов малого таза; различия в частоте регистрации генотипа между данными группами статистически достоверны $\left(\mathrm{OR}=5,67 ; \mathrm{X}^{2}=5,58\right.$; $p<0,05)$. Это позволяет рассматривать данный генотип в качестве предиктора развития осложнений УГХИ у женщин. Достоверных различий в частоте регистрации данного генотипа между другими группами обследуемых не установлено.

Генотип TGF- $\beta_{1}{ }^{*} 869 C / C$ в обследованной группе пациенток был наименее представленным (12,5\%; в отдельных группах 5,0-15,0\%). Достоверных раз- личий в частоте регистрации данного генотипа между группами обследуемых не установлено.

\section{Заключение}

В результате проведенных исследований установлено наличие достоверных ассоциаций частоты регистрации полиморфных вариантов генов: IL-6, TGF- $\beta_{1}$, IL-10 и MBL2 с повышенным риском развития осложнений УГХИ, которые могут привести к нарушениям репродуктивной функции (рис. 2).

Частота регистрации генотипов $I L-6^{*}-174 C / C$, IL-10*-1082G/A, TGF- $\beta_{1}{ }^{*}-915 \mathrm{G} / \mathrm{C}, \mathrm{TGF}-\beta_{1}{ }^{*}-869 \mathrm{~T} / \mathrm{C}$ и $M B L 2^{*}-204 G / G$ у пациенток с осложненным клиническим течением УГХИ (ВЗОМТ) была достоверно выше $(0,05<p<0,001)$, чем у пациенток с неосложненным течением заболевания (нижние отделы урогенитального тракта), что позволяет рассматривать данные генотипы как вероятные молекулярно-генетические маркеры повышенного риска развития осложнений УГХИ, приводящих к нарушениям репродуктивной функции пациенток.

В ходе выполнения исследования также был установлен ряд генотипов генов IL-10, TGF- $\beta_{1}$ $\left(\mathrm{IL}-10^{*}-1082 \mathrm{G} / \mathrm{G}, \mathrm{TGF}-\beta_{1}{ }^{*}-869 T / T\right)$, которые могут играть протективную роль в развитии осложнений (ВЗОМТ) у пациенток с УГХИ; данные генотипы достоверно реже $(0,01<p<0,001)$ регистрировались у больных с УГХИ органов малого таза в сравнении с больными с неосложненным течением УГХИ.

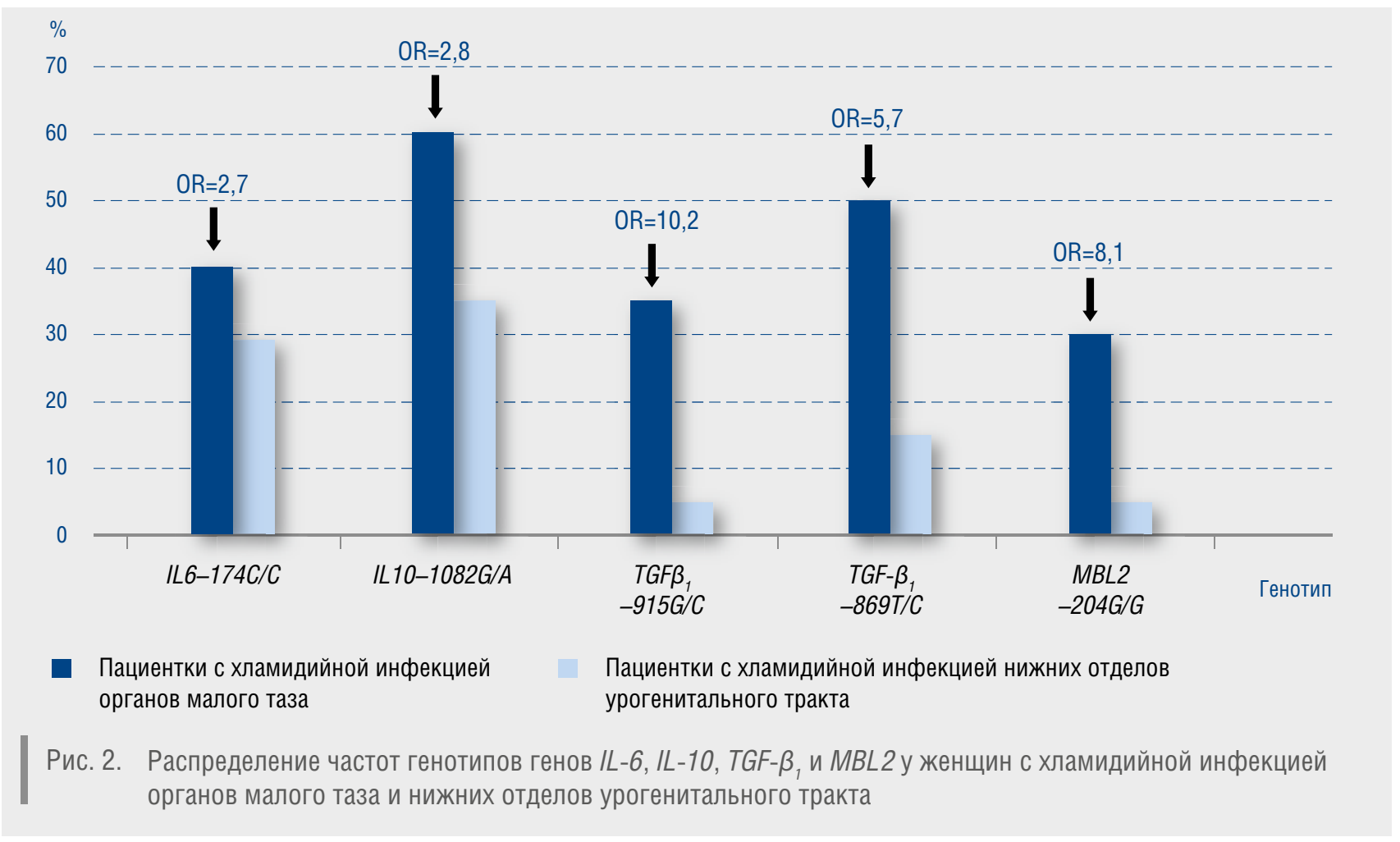


Полученные данные позволяют использовать определение полиморфизма генов с целью прогнозирования осложненного течения УГХИ и предотвращать развитие осложнений при своевременном определении риска.

В процессе исследования был также обнаружен ряд генотипов, которые могут являться потенциальными молекулярно-генетическими маркерами повышенного риска развития вторичного (трубного) бесплодия у женщин (IL-6*-174C/C, IL-10*-592C/C, IFN-ү *874T/T), а также маркерами-протекторами в отношении развития вторичного бесплодия (IL-10*-592A/A, IFN-ץ*874T/A). Содержание этих генотипов достоверно различалось в группах пациенток с бесплодием и здоровых лиц $(p<0,001)$.

Результаты проведенных исследований вносят вклад в изучение молекулярно-генетических основ развития осложнений УГХИ, приводящих к нарушению репродуктивной функции пациентов, и могут быть использованы при разработке персонализированного подхода к выбору тактики ведения и лечения пациентов с УГХИ.

\section{Литература}

1. Resursy i deyatel'nost' meditsinskikh organizatsiy dermato-venerologicheskogo profilya. Zabolevaemost' infektsiyami, peredavaemymi polovym putem, zaraznymi kozhnymi boleznyami i boleznyami kozhi za 2010-2011 gody (Statisticheskie materialy). [Ресурсы и деятельность медицинских организаций дерматовенерологического профиля. Заболеваемость инфекциями, передаваемыми половым путем, заразными кожными болезнями и болезнями кожи за 2010-2011 гг. (Статистические материалы)]
2. Öhman H., Triitinen A., Halttunen M. et al. Cytokine polymotphisms and severity of tubal damage in women with Chlamydia-associated infertility. H. Öhman. J. f infect dis. 2009; 199. 1353 —9.

3. Hvid M., Baczynska A. , Deleuran B., Fedder J., Knudsen H., Christiansen G., Birkelund S. Interleukin-1 is the initiator of Fallopian tube destruction during Chlamydia trachomatis infection. Cell Microbiol 2007.
4. Öhman H., Triitinen A., Halttunen M. et al. IL-10 polymorphism and cell-mediated immune response to Chlamydia trachomatis. H. Öhman. Genes and Immunity 2006, 7. 243-249.

5. Fife M.S., Gutierrez A., Ogilvie E.M., Stock C.J., Samuel J.M., Thomson W., Mack L.F., Lewis C.M., Woo P. Novel IL10 gene family associations with systemic juvenile idiopathic arthritis. Arthritis Res Ther 2006; 8(5):R

об авторе:

К.И. Плахова — к.м.Н., старший научный сотрудник отдела инфекций, передаваемых половым путем, ФГБУ «ГНЦДК» Минздрава России, Москва

Работа была выполнена в рамках Федеральной целевой программы «Научные и научно-педагогические кадры инновационной России» в отделе инфекций, передаваемых половым путем (рук. - д.м.н. Рахматулина М. Р.), и в отделе лабораторной диагностики ИППП и болезней кожи (рук. - д.м.н. Фриго Н. В.) по итогам гранта Министерства образования и науки «Разработка технологии молекулярной диагностики индивидуального генетического риска развития нарушений репродуктивной функции, ассоциированных с урогенитальной хламидийной инфекцией у человека». Государственный контракт № 02.740.11.0774 от 12 апреля 2010 г. 